\title{
Towards A Typology Of Parental Behaviors, Attitudes, And Beliefs About School
}

\author{
Daniel Pelletier, Ph.D., University of Quebec in the Outaouais, Canada \\ Pierre Collerette, Ph.D., University of Quebec in the Outaouais, Canada \\ Gilles Turcotte, Ph.D., University of Quebec in the Outaouais, Canada \\ Alexandre Beaulieu, Ph.D., University of Quebec in the Abitibi-Temiscamingue, Canada
}

\begin{abstract}
The social and academic experiences of children and adolescents in school are a major concern for parents and their characteristics as protection or risk factors for their children's adaptation has been extensively studied. However, few studies have dealt with the behaviors, attitudes and beliefs of parents about the schools their children are enrolled in. The aim of this study was to address that issue. A random sample of 1297 parents drawn from 8 large Canadian school boards took part in standardized individual interviews which yielded both quantitative and qualitative information on demographics, family structure, time management, attitudes, behaviors and beliefs about school, along with data on their children's school achievement and overall adaptation. A dynamic grouping analysis was applied to salient variables which generated a four group typology of parents: collaborators, critics, overwhelmed, and ill-equipped. Results further indicated that only a very small number of participants did not value education, as opposed to earlier findings where they represented a significant proportion of parents. Practical implications of these results for school administrators, parents and educators will be discussed.
\end{abstract}

Keywords: Parental Behaviors; Attitudes and Beliefs About School; Canadian Schools

\section{LITERATURE REVIEW}

$\mathscr{I}$ $\mathrm{t}$ is a well known fact that school achievement is affected by multiple factors among which parental influences stand out (Coleman, 1966; Collerette \& Pelletier, 2009; Sanders, 2001; Teddlie \& Reynolds, 2000). Many scholars and practitioners in the education field have endeavoured to describe the nature of this influence, their research ending with differential conclusions: parents who do get involved in their children's school experience do it for various reasons among which contingencies, resources and values play a key role (Gewirtz, Bowe \& Ball, 1995; Hoover-Dempsey \& Sandler, 1995).

In a comprehensive meta-analysis dealing with this issue, Fan \& Chen (1999) reported that most published papers had little or no sound empirical data to back up their assertions and recommendations. A moderate but significant relationship between parental involvement and school achievement was found but it seems that parental values and beliefs about the importance of school along with performance expectancies were more important factors than the actual supervision of homework, giving important indications as to the type of parental involvement which could foster better school results for children.

Mapp, Johnson, Strickland \& Meza (2008) also report a similar type of indirect effect: parental support and involvement does not have to be instrumental or technical in nature to be effective. It seems that for children, the belief that their school experience and achievement are important issues for their parents is a driving force in the elementary school years which declines during adolescence with maturation, self-directed goals and control/supervision issues (Baumrind, 1991; Epstein, Sanders, Simon, Salinas, Jansorn, \& Van Voorhis, 2002).

Even though parental involvement appears to be the central factor at play here (Jeynes, 2007; 2005; Sheldon \& Van Voorhis, 2002; Stelmack, 2002; Teddlie \& Reynolds, 2000) direct parental supervision of 
homework does not seem to generate very positive results (Cooper, Lindsay \& Nye, 2000; Hill \& Tyson, 2009). Parents often get impatient or overbearing, they do not always have the required background to effectively help their children, and it seems that getting their children to finish quickly is one of their motivations.

Very few studies have dealt with the cultural aspects of school from a regional standpoint, even though many papers regularly report major differences in school achievement between, school boards, counties, states, provinces and even countries. In 2009, a pilot study conducted by the authors indicated that between-regions differences in school achievement figures could be linked to differential attitudes, values and beliefs about school from parents and the general population (Collerette \& Pelletier, 2009).

A three cluster group structure of parents was identified in the pilot study: a) collaborating parents, characterized by positive attitudes towards their children's school and average diplomas and training; b) illequipped parents with positive attitudes towards school but under average diplomas and training; c) reluctant parents with positive values regarding the importance of education but negative opinions about their children's school, along with average to above average schooling and training.

The most interesting part of these results was the relative absence of parents which did not value education, i.e. parents who value paid work over school and have, themselves, experienced little success in the educational realm. For many years, the dropout phenomenon was linked to the influence of such parents for whom education was deemed not important. Indeed, up the mid 70s, a high school diploma could still be enough to land a quality job in major enterprises or in the public and parapublic sectors. However, contemporary conditions are very different and most parents within ours ample seemed to recognize that in today's economy and job market, education and degrees were more than ever important assets.

Further inquiries based on previous research (Pelletier, 2001) indicated that one other factor should be included in the equation: time constraints. Many of the reluctant parents were either heading single-families or double income families with both mother and father working full-time. Furthermore, regional statistics indicated that these two family configurations were more frequent in low achieving regions, even though the overall SES was higher. A significant relationship between regional school achievement scores and the proportion of parents belonging to each of the three aforementioned groups was also found: regions with the lowest scores had a significantly higher proportion of « reluctant » parents.

\section{PROBLEM STATEMENT, AIM, RESEARCH QUESTIONS}

The importance of parental values, attitudes and involvement in their children's school experience is undeniable. However, very little research has dealt with more macroscopic issues of cultural regional differences regarding education. A previous pilot-study generated interesting insights into possible clusters of parents characterized by differential profiles linked to higher or lower levels of school achievement. However, the pilot study had a limited sampling base and relied on first generation questionnaires which needed to be revised. The aim of this research was to generate a typology of relevant parental beliefs, values and attitudes regarding school which could be used to add to our understanding of some the many factors which impact school achievement at a macroscopic level. Three research questions were investigated:

1. Could the three cluster typology identified in the pilot study be replicated with a larger sample covering more regions and school boards?

2. What if any differences are there in terms of proportions of parents within each cluster from one region/school board to the other?

3. What is the relationship between selected regional/school board cluster profiles and success and dropout rates? 


\section{METHOD}

\section{Participants}

A random sample of 1297 parents drawn from 8 school boards in the province of Quebec (Canada) took part in the study. All school boards had a similar demographic profile and comparable sizes. Each of them also covered a similar territory including both urban and rural environments. Participants were randomly drawn from a pool of potential respondents which had a child registered in the participating school boards. An random draw of 300 respondents from each school board was used to build the sample, contact parents by phone and elicit their collaboration. The objective was to reach an average of 120 participants for each school board. Once the wrong numbers and no answer numbers are eliminated, the pool was reduced to $67 \%$ of the initial draw, with a final response rate of $80,6 \%$.

\section{Instruments}

A 70 item standardized interview protocol was specifically designed and used for this study, based on the initial questionnaire of the pilot study. Both open and multiple choice questions were used and their face validity was deemed as high by a panel of judges. The variety of question and answer formats did not allow the use of traditional analyses of the psychometric properties of the instrument which was much closer in form and contents to a survey. The interview protocol yielded both quantitative and qualitative information on demographics, family structure, time management, attitudes, behaviors and beliefs about school, along with data on children's school achievement and overall adaptation. Amalgamated school records and demographic information were obtained through the school boards and various government agencies.

\section{Procedure}

A team of interviewers was selected and trained for the interviews. Parents were called at home and the nature, scope and objectives of the interview were explained to them, along with the ethical safeguards used to protect their identity. Once the parent accepted to participate, the 15 minute interview began and answers were directly recorded in a software platform.

\section{Data treatment and analytic strategy}

Numeric data was integrated in the software while open answers were synthesized and categorized ex post facto using a basic contents analysis procedure. A unified data set was compiled using S.P.S.S. software version 20; data integrity was verified and missing values were treated using a linear interpolation procedure. A combination of cluster and univariate analyses along with descriptive statistics were used to answer the research question.

\section{RESULTS}

Results will be presented in a sequential mode in reference to each of the three research questions.

Question 1: Could the three cluster typology identified in the pilot study be replicated with a larger sample covering more regions and school boards?

Cluster analyses with iterations were performed on the data set setting the number of clusters at three, then at four. The three cluster equation generated a non convergent solution after 10 iterations, but the four cluster equation achieved convergence within the limit. Characteristics of the clusters and corresponding Anova results are presented in Table 1. Cluster 1 includes $38 \%$ of the sample; cluster $2-10 \%$; cluster $3-35 \%$; cluster $4-17 \%$. 
Table 1: Parental clusters and Anova results

\begin{tabular}{|l|c|c|c|c|c|c|}
\hline \multicolumn{1}{|c|}{ Grouping variables } & CL-1 & CL-2 & CL-3 & CL-4 & F & Sig. \\
\hline As a child i liked going to school & 3,61 & 3,35 & 3,56 & 3,52 & 3,683 &, 012 \\
\hline Schools expect too much of parents & 2,68 & 2,08 & 2,64 & 2,70 & 10,241 &, 000 \\
\hline Need more time to supervize homework & 3,24 & 2,75 & 3,13 & 3,42 & 10,465 &, 000 \\
\hline Homework is a source of stress at home & 2,39 & 2,21 & 2,39 & 2,30 & 1,243 &, 293 \\
\hline My children like their school & 3,60 & 3,20 & 3,40 & 3,53 & 10,252 &, 000 \\
\hline School does what it should to foster success & 3,30 & 2,92 & 3,24 & 3,45 & 10,395 &, 000 \\
\hline Education was better when i was in school & 3,31 & 3,02 & 3,21 & 3,49 & 14,780 &, 000 \\
\hline Discussion about grades with children & 3,16 & 2,79 & 2,95 & 3,36 & 20,156 &, 000 \\
\hline Family time management problems & 1,65 & 1,65 & 1,82 & 1,81 & 3,578 &, 014 \\
\hline Culture oriented & 3,17 & 2,56 & 2,98 & 3,43 & 9,530 &, 000 \\
\hline Salary bracket & 5,01 & 4,76 & 5,00 & 4,19 & 16,537 &, 000 \\
\hline Occupational prestige & 2,88 & 2,52 & 2,80 & 2,59 & 5,689 &, 001 \\
\hline Age & 38,15 & 52,22 & 44,35 & 30,55 & 2782,889 &, 000 \\
\hline Schools have improved over the past 10 years & 2,92 & 2,42 & 2,84 & 3,12 & 13,002 &, 000 \\
\hline
\end{tabular}

Characteristics of each of the four clusters are synthesized in Figure 1.

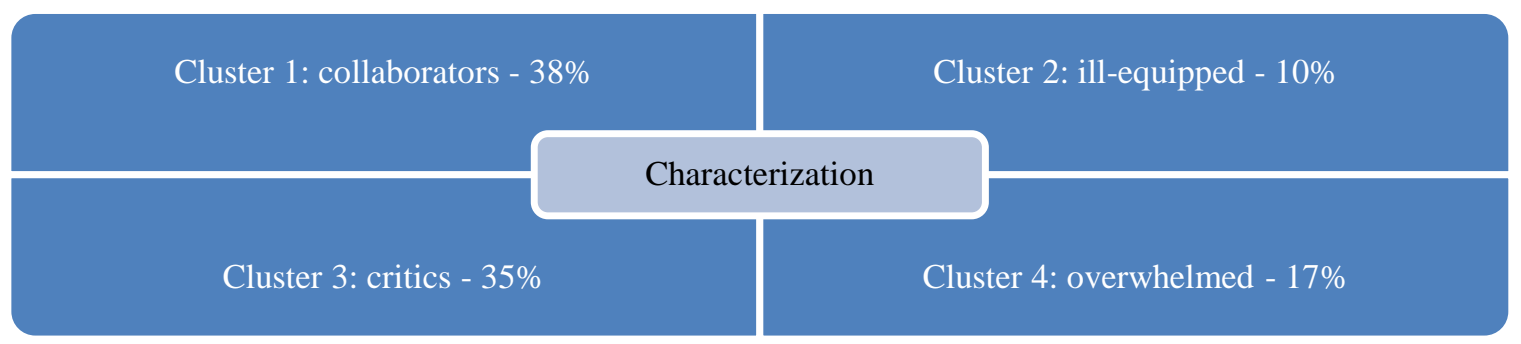

Figure 1: Characterization of the four clusters

Question 2: What if any differences are there in terms of proportions of parents within each cluster from one region/school board to the other?

A crosstabulation of clusters by school boards/regions was applied to the data, generating significant differences in terms of proportions of parents from each group according to the school board/region (see Table 2).

Table 2: Proportions of parents within each cluster for each school board

\begin{tabular}{|l|c|c|c|c|c|c|c|c|}
\hline \multicolumn{1}{|c|}{ Clusters } & S.B. 1 & S.B. 2 & S.B. 3 & S.B. 4 & S.B. 5 & S.B. 6 & S.B. 7 & S.B. 8 \\
\hline Collaborators & $38,9 \%$ & $34,0 \%$ & $26,7 \%$ & $41,7 \%$ & $33,8 \%$ & $32,3 \%$ & $46,2 \%$ & $34,3 \%$ \\
\hline Ill-equipped & $3,1 \%$ & $10,7 \%$ & $17,8 \%$ & $11,7 \%$ & $16,9 \%$ & $29,2 \%$ & $5,4 \%$ & $11,2 \%$ \\
\hline Critics & $29,5 \%$ & $32,0 \%$ & $47,8 \%$ & $32,6 \%$ & $40,8 \%$ & $33,8 \%$ & $35,5 \%$ & $44,1 \%$ \\
\hline Overwhelmed & $28,5 \%$ & $23,3 \%$ & $7,8 \%$ & $13,9 \%$ & $8,5 \%$ & $4,6 \%$ & $12,9 \%$ & $10,5 \%$ \\
\hline
\end{tabular}

$\mathrm{Khi}^{2}=123,476 ; \mathrm{p}<.0001$

Question 3: What is the relationship between selected regional/school board cluster profiles and success and dropout rates?

In order to examine the relationship between selected profiles and school achievement, 2 descriptive analyses were performed. The first one compares proportions of overwhelmed parents and dropouts for each school board (see Figure 2). 


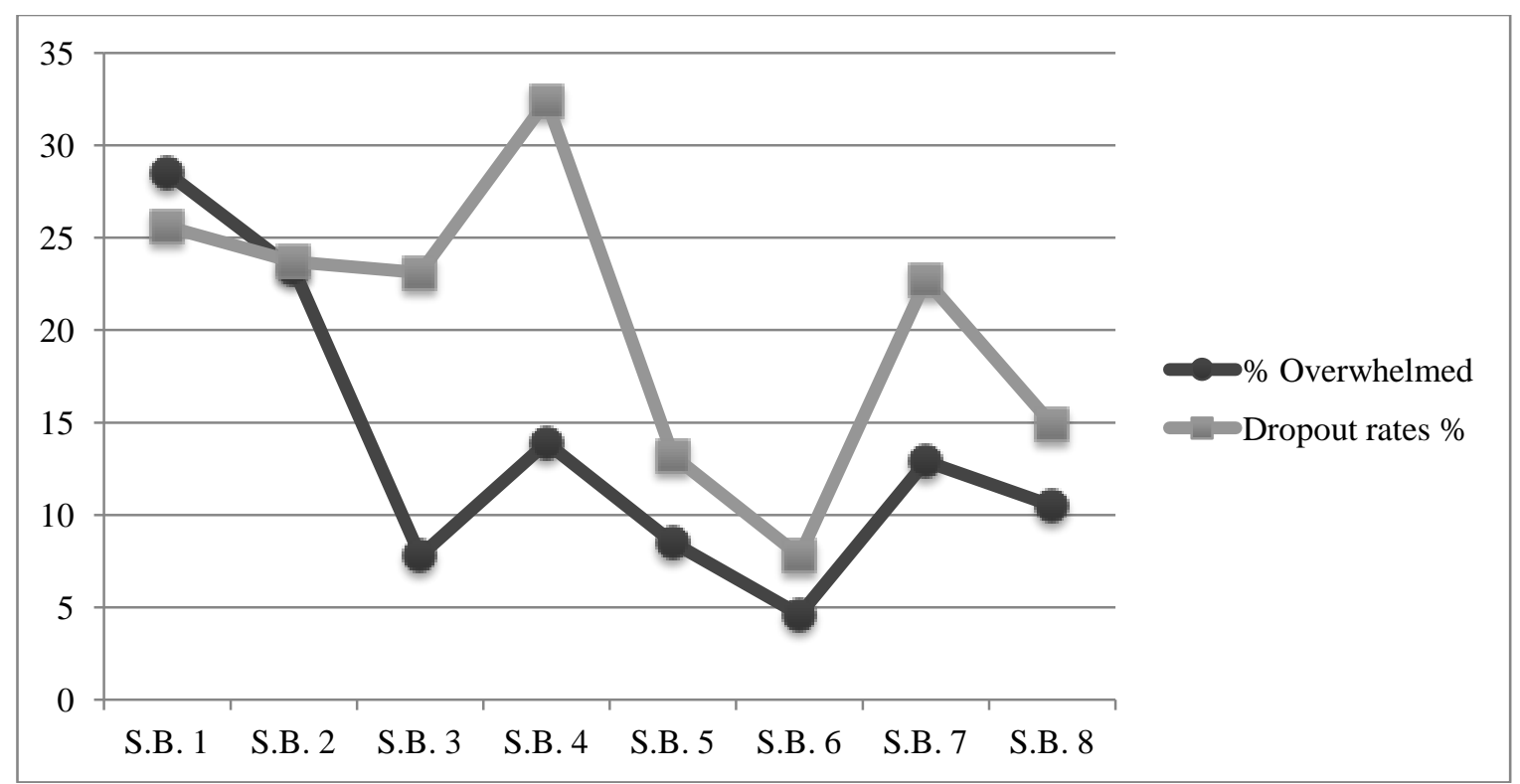

Figure 2: Proportions of overwhelmed parents and dropouts for each school board.

The second analysis compares proportions of collaborating parents and overall success rates in mathematics and reading for each school board (see Figure 3).

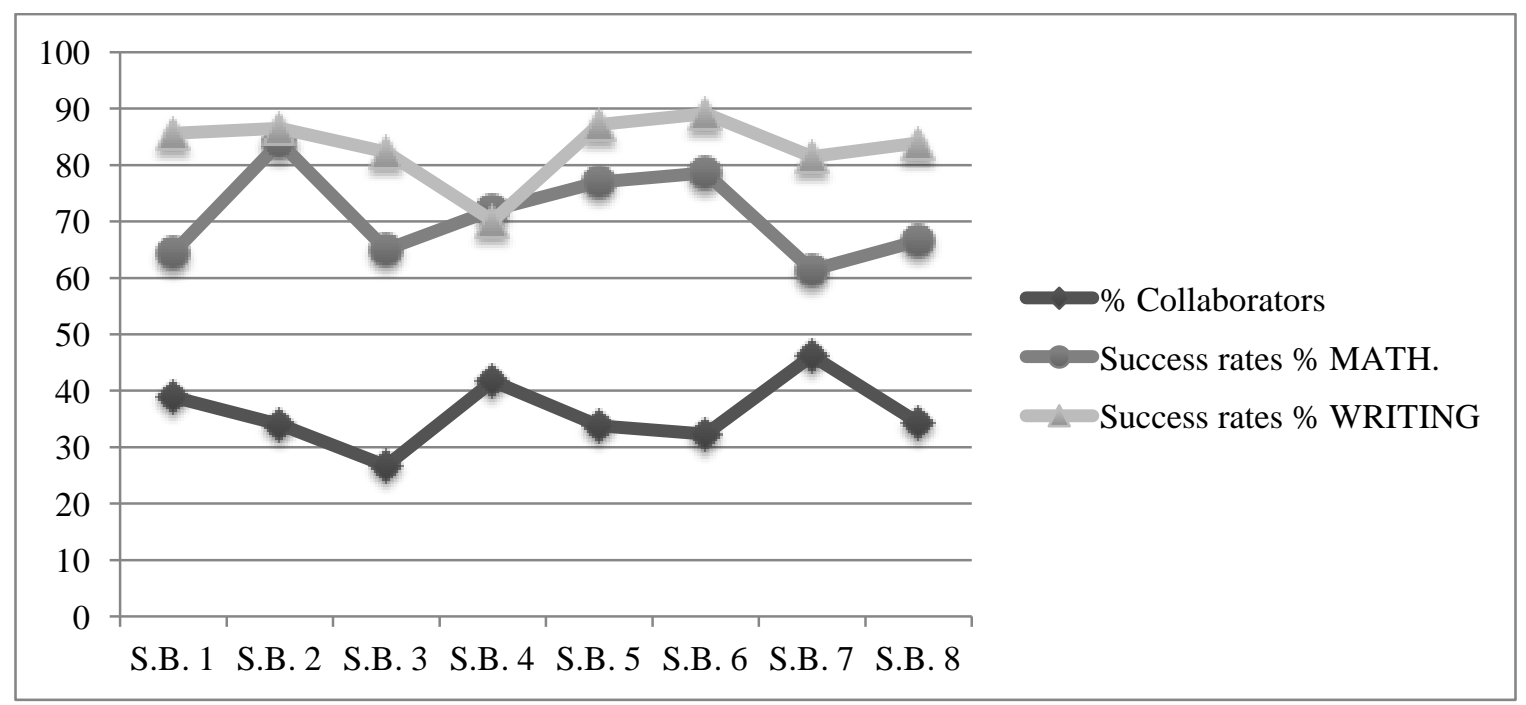

Figure 3: Proportions of Collaborators and overall success rates in mathematics and reading for each school board

\section{DISCUSSION}

\section{Research question 1}

The grouping pattern that was generated through the first series of analyses was somewhat different from what was expected, since the pilot study indicated that a three group solution had a good fit with the data. However, with a larger sample and a more refined instrument, differences were bound to appear. The four clusters uncovered here represent a scope of parental beliefs, attitudes and characteristics which are quite distinctive. Collaborators, which represent $38 \%$ of the sample, appear to be in the best position to support their children at school: they are educated, culturally oriented, and have positive opinions about their school experience as well as their children's. The second most important group was called Critics (35\% of the sample) because of less positive opinions on a 
variety of specific topics while still having an overall positive appreciation for their children's school. The third group (17\% of the sample) was labeled Overwhelmed; parents in this cluster are the youngest (average age 30), their own school experience was better than their children's, they believe that schools expect too much of parents and have time management issues while being culture oriented, are not actively involved in their children's schooling and they have low scores on the occupational prestige and culture orientation scales. The fourth group (10\% of the sample) was labeled Ill-equipped; parents in this cluster are significantly older (average age 52), their own school experience was not optimal, they are not actively involved in their children's schooling and they have low scores on the occupational prestige and culture orientation scales.

\section{Research question 2}

Results indicated that substantial differences in terms of proportions for each cluster could be observed from one school board to the other. This could indicate that a highly individualized mosaic of factors affects parental attitudes, beliefs and expectations about school along lines which are certainly more complex than the usual rich/poor or rural/urban dichotomies.

\section{Research question 3}

The third question represents an attempt to relate specific clusters to outcomes such as success and dropout rates. Without going into each of the possible relationships, two specific findings stand out. The first finding is based on the relative parallel curves generated by the respective proportions of overwhelmed parents and dropouts in each school board. Without overanalyzing these results, they point to a possible effect of specific attitudinal mind sets within sub-groups of parents which could adversely affect students, directly or indirectly. One could also hypothesize that a common hidden factor such as local job markets is at play here. The second finding is conversely related: no such parallelism was observed between positive outcomes, such as success rates in mathematics and writing and the respective proportions of the most positive cluster-Collaborators. As it is often the case, recipes for disaster seem to be easier to identify than recipes for success.

\section{CONCLUSION}

Though exploratory in nature, this research indicates that parental influences on their children's school experience may be very different from one environment to the other. This lends credence to a growing belief in localized approaches which take into account the differential needs and proportions of parents identified in the cluster analysis procedure used here, from one school board, territory or region to the other.

\section{AUTHOR INFORMATION}

Daniel Pelletier, Ph.D., University of Quebec in the Outaouais, P.O. Box 1250, Station Hull, Gatineau (QC) J8X 3X7, Canada. Email: daniel.pelletier@uqo.ca (Corresponding author).

Pierre Collerette, Ph.D., University of Quebec in the Outaouais, P.O. Box 1250, Station Hull, Gatineau (QC) J8X $3 \times 7$, Canada.

Gilles Turcotte, Ph.D., University of Quebec in the Outaouais, P.O. Box 1250, Station Hull, Gatineau (QC) J8X $3 \times 7$, Canada.

Alexandre Beaulieu, Ph.D., University of Quebec in the Abitibi-Temiscamingue, 445 boul. de l'Université, RouynNoranda (QC) J9X 5E4, Canada. Email: alexandre.beaulieu@uqat.ca

\section{REFERENCES}

1. Baumrind, D. (1991). Parenting styles and adolescent development. In J. Brooks-Gunn, R. Lerner \& A. C. Peterson (Eds.), The encyclopedia of adolescence (pp. 746-758). New York: Garland. 
2. Coleman, J. A. (1966). Equality of Educational Opportunity Study. Washington, DC: U.S. Department of Health, Education, and Welfare.

3. Collerette, P., \& Pelletier, D. (2009). Résultats de l'enquête comparative entre l'Outaouais et le Saguenay sur la culture régionale à l'endroit de la scolarisation et de la réussite scolaire. Gatineau : Rapport d'étude pour la Table MELS-ADIGECS Outaouais.

4. Cooper, H.M., Lindsay, J.J., \& Nye, B. (2000). Homework in the home: How student, family, and parenting-style differences relate to the homework process. Contemporary Educational Psychology, 25(4), 464-487.

5. Epstein, J., Sanders, M., Simon, B., Salinas, K., Jansorn, N., \& Van Voorhis, F. (2002). School, family, and community partnerships: Your handbook for action (2nd ed.). Thousand Oaks, CA: Corwin Press.

6. Fan, X., \& Chen, M. (April 1999) Parental Involvement and Student's Academic Achievement: a Metaanalysis. Paper presented at the Annual Meeting of the American Educational Research Association. Montreal, Canada.

7. Gewirtz, S., Ball, S., \& Bowe, R. (1995). Markets, choice and equity in education. Bristol, PA: Open University Press.

8. Gray, J. (2004). Frames of Reference and Traditions of Interpretation:Some Issues in the Identification of «Under-Achieving » Schools. British Journal of Educational Studies, 52 (3), 293-309

9. Hill, N.E., \& Tyson, D.F. (2009). Parental involvement in middle school: A meta-analytic assessment of the strategies that promote achievement. Developmental Psychology. 45(3). 740-763.

10. Hoover-Dempsey, K.V., \& Sandler, H.M. (1995). Parental Involvement in Children's Education: Why does it make a difference. Teachers College Record, 97, 310-331.

11. Jeynes, W.H. (2007). The Relationship between Parental Involvement and Urban Secondary School Student Academic Achievement: A Meta-Analysis. Urban Education, 42 (1), 82-110.

12. Jeynes, W. H (2005). A Meta-Analysis of the Relation of Parental Involvement to Urban Elementary School Student Academic Achievement. Urban Education, 40(3), 237-269.

13. Mapp, K., Johnson, V.R., Strickland, C.S., \& Meza, C. (2008). High School Family Centers: Transformative Spaces Linking Schools and Families in Support of Student Learning. Marriage \& Family Review, 43 Issue 3/4, 338-368.

14. Pelletier, D. (2001). Quelques variables sociodémographiques associées au risque de décrochage des élèves de l'Outaouais. Rapport d'étape. Gatineau : Université du Québec en Outaouais.

15. Sanders, M.G. (2001). The role of « community » in comprehensive school, family, and community partnership programs. The Elementary School Journal, 102, 19-34.

16. Sheldon, S.B., \& Van Voorhis F.L. (2004). Partnership Programs in US Schools: Their Development and relationship to Family Involvement Outcomes. School Effectiveness and School Improvement15 (2), $125-$ 148 .

17. Stelmack, B. (2004). Parental Involvement: A Research Brieffor Practitioners. Calgary: University of Alberta.

18. Teddlie, C., \& Reynolds, D. (2000). The International Handbook of School Effectiveness Research. London: Falmer Press. 
NOTES 